\title{
EXHIBIT OF MICRO-ORGANISMS, WITH SOME REMARKS.
}

\author{
By EDMOND J. McWEENEY, M.A., M.B., \&c.; \\ Pathologist, Mater Misericordiæ Hospital ; Lecturer on Pathology, \\ Catholic University Medical School.
}

[Read in the Section of Pathology, January 10, 1890.]

IN laying the following pure cultures before the Academy to-night, I shall confine myself to the briefest possible allusion to each, They have all been made by me when working last November in the Laboratory of Dr. Robert Koch at the Hygiene Institute of the Royal University of Berlin.

The following organisms were then shown, and a few words said about each :-

\section{Non-Pathogenic Organisms:-}

Bacillus subtilis (Ausstrich-culture on agar-agar)

$$
\begin{gathered}
, \quad \text { megaterium }, ", " \\
" \quad \text { prodigiosus (on potato) } \\
\text { "fluorescens (Stich-culture in gelatine) } \\
\text { Spirillum rubrum (in an Esmarch's tube) }
\end{gathered}
$$

\section{Pathogenic Organisms:-}

Bacillus anthracis (Ausstrich on agar-agar)

" mallei (glanders) (Ausstrich: also on potato)

" tuberculosis (Ausstrich on glycerine agar)

" pneumoniæ crouposæ (Friedländer) (Ausstrich)

" pyocyaneus (Stich in gelatine which had liquefied)

" of swine-erysipelas (Stich in gelatine)

$"$ 'Yyphosus (on potato)

" Cholera Asiatica (Koch) (Ausstrich)

Micrococcus tetragonus (Stich in gelatine) 
In explanation of the not very typical character presented by some of the cultures, I may say that regard has necessarily been paid, in the selection of the substratum, rather to the portability of the specimen than to securing the most typical appearance. It is this circumstance which has caused me to select oblique (Schräg) agar-agar in so many cases. All the cultures are pure with the exception of that of the typhoid bacilli on potato, which has become contaminated with a spot of the common yellow sarcina of air. I have come provided with microscopic slides illustrative of each species, but the microscopic accommodation at the disposal of exhibitors permits me to show only two objects-viz., a so-called "Klatsch" preparation of the anthrax bacillus showing its peculiar method of growth, and a slide of a very interesting organism, cultures of which I am unfortunately not in a position to lay before the Section-the Nicolaier-Rosenbach bacillus tetani. The chief biological points in regard to this organism have been lately worked out in detail by a Japanese investigator, Kitasato, in Dr. Koch's Laboratory. He found it strictly anaerobic, gas-forming, and capable of secreting a peculiar pigment. Its pathogenicity seems, according to the most recent researches, notably Hoegler's [quoted in Centralbl. f. Pathologie for Jan., 1890], to be firmly established. My specimens show its peculiar method of spore formation, by which it is at once distinguished from allied species. On one, sometimes both ends of the rod, a spherical protuberance makes its appearance, which becomes detached, and possesses the resistance against external influences characteristic of spores. When in this condition the organisms closely resemble minute, round-headed pins. The establishment of pure cultures of this organism is at all times a matter of considerable difficulty. As this is the first occasion on which specimens of this remarkable bacillus-which acts by means of its ptomaine named tetanotoxin by Brieger, who isolated it-have been exhibited in Dublin, I trust the Academy will excuse the length at which $I$ have referred to it. 